\title{
Differences in boys' and girls' attachment to pets in early-mid adolescence
}

\begin{abstract}
The precise nature of attachment to pets and differences between girls' and boys' relationships at age 11, 13 and 15 years are investigated in this paper. Data from the 2010 Health Behaviour in School-aged Children (HBSC) survey in Scotland were used to examine qualities of adolescents' attachments to their pet dogs, cats and small mammals. Survey participants $(\mathrm{N}=2,472)$ answered pet ownership questions and completed the 'Short Attachment to Pets Scale' (SAPS). Multivariate analysis revealed main effects of age, sex and pet type, but no interaction effects. There is a pattern of weakening attachment to pets with increasing age, with emotional support qualities of attachment receiving higher ratings from girls, and stronger attachments evident with dogs. These findings enhance understanding of the role played by pets in the broader relational context of adolescents' lives, and help to identify how we might intervene to support adolescents experiencing socioemotional difficulties or life disruptions.
\end{abstract}




\title{
Differences in boys' and girls' attachment to pets in early-mid adolescence
}

\author{
Janine C Muldoon ${ }^{1}$, Joanne M Williams ${ }^{1}$, \& Candace Currie ${ }^{2}$ \\ ${ }^{1}$ University of Edinburgh, ${ }^{2}$ University of St Andrews
}

Dr Janine C Muldoon (corresponding author), Clinical and Health Psychology, School of Health in Social Science, University of Edinburgh, Doorway 6, Medical Quad, Teviot Place, Edinburgh, UK, EH8 9AG. janine.muldoon@ed.ac.uk Tel: +44 (0)1383 861280 Professor Joanne M Williams, Clinical and Health Psychology, School of Health in Social Science, University of Edinburgh, Doorway 6, Medical Quad, Teviot Place, Edinburgh, UK, EH89AG. jo.williams@ed.ac.uk Tel: +44(0)1316509962 Professor Candace Currie, Child and Adolescent Health Research Unit (CAHRU), School of Medicine, Medical \& Biological Sciences, North Haugh, St Andrews, Fife, UK, KY16 9TF. cec53@st-andrews.ac.uk Tel: +44(0)1334 461741 


\title{
Differences in boys' and girls' attachment to pets in early-mid adolescence
}

\begin{abstract}
The precise nature of attachment to pets and differences between girls' and boys' relationships at age 11, 13 and 15 years are investigated in this paper. Data from the 2010 Health Behaviour in School-aged Children (HBSC) survey in Scotland were used to examine various qualities of adolescents' attachments to their pet dogs, cats and small mammals. Survey participants $(\mathrm{N}=2,472)$ answered pet ownership questions and completed the 'Short Attachment to Pets Scale' (SAPS). Multivariate analysis revealed main effects of age, sex and pet type, but no interaction effects. There is a pattern of weakening attachment to pets with increasing age, with emotional support qualities of attachment receiving higher ratings from girls, and stronger attachments evident with dogs. These findings enhance understanding of the role played by pets in the broader relational context of adolescents' lives, and help to identify how we might intervene to support adolescents experiencing socioemotional difficulties or life disruptions.
\end{abstract}

Key words: adolescence; age; animals; attachment; children; pets 
Differences in boys' and girls' attachment to pets in early-mid adolescence

This paper focuses on a core area of Human-Animal Interaction (HAI) research: attachment to pets. We explore differences in the strength and quality of adolescents' attachment to different pets according to their age and sex, and build on emerging evidence that these relationships are influential during this important developmental phase (Mueller, 2014a; 2014b). Central to our study is Attachment Theory, an influential theoretical area of both developmental psychology (Bucci, Roberts, Danquah, \& Berry, 2015; Cassidy, Jones, \& Shaver, 2013; Cassidy \& Shaver, 1999) and child-animal interaction research (Rockett \& Carr, 2014; Meehan, Massavelli, \& Pachana, 2017, Mueller, 2014a, Payne, Bennett, \& McGreevy, 2015).

\section{The importance of looking closely at the nature of attachment to pets}

Increasingly, there is recognition of the beneficial impact of human-animal interaction, particularly for those experiencing high levels of stress or low levels of support (Garrity, Stallones, Marx, \& Johnson, 1989; Havener et al., 2001). This has prompted a surge of interest in incorporating pets and other animals within various therapeutic approaches. It appears that engagement with unfamiliar/unknown animals can bring emotional and behavioral benefits (e.g., Chur-Hansen et al., 2014; Nimer \& Lundhal, 2007). Therefore, the potentially stronger relationships developed within the family setting may carry even greater significance for adolescent socio-emotional wellbeing. In particular, if we understand the nature of children/adolescents' relationships with pet animals, the knowledge gained may be usefully applied within the design of animal-assisted therapy, animal welfare programmes, and in interventions aimed at vulnerable children.

Although Carr and Rockett (2017) note that animals cannot replace human attachment figures, they highlight recent evidence that pets can be 'significant others' for children/adolescents. This may be particularly true of those who have no siblings, or are the 
youngest in the family, as they can exhibit stronger attachment to their pets (Westgarth et al., 2013). Yet even amongst those with siblings, relationships with pets can be stronger and more positive than those with brothers or sisters during certain phases of their development and family life (Cassels, White, Gee, \& Hughes, 2017). Importantly, in families where relationships with parents/guardians and/or siblings have been severely disturbed, a pet may have been one of the few sources of responsive, reliable and consistent warmth and affection available to the child (Furnival, 2011). This is worth considering in relation to the developing child more generally, where relationships and expectations associated with increasing maturity are potentially in flux and require renegotiation. A relationship with a pet is perhaps less complex and more consistent/steady than those with other humans. Therefore, pets may play an important role during difficult transitions when relationships can be disrupted (Muldoon, 2005; Muldoon \& Williams, 2018). Accordingly, there are implications for people working with children and young people, particularly around key transition points and with the most vulnerable young people in society.

\section{The influence of age on attachment to pets}

Many children talk about animals with enthusiasm (McNicholas \& Collis, 2001; Morrow, 1998; Muldoon, Williams, \& Lawrence, 2016), but there is evidence to suggest that attachment to pets wanes with age (see Jalongo, 2015). First, there appears to be less involvement with family pets during adolescence than earlier in childhood. Seventy-five percent of adolescents in Mathers et al.'s (2010) study, for example (mean age 15.9 years), reported very little interaction with their pets. Moreover, time spent caring for/playing with a pet was not associated with better health and well-being. In keeping with this finding of diminishing interactions, attachment to pets has been found to decrease with age (MarsaSambola et al., 2016). Muldoon, Williams, Lawrence, and Currie (2019) looked at children/adolescents with different types of pet, finding attachment to be stronger in the 
youngest age group regardless of the type of pet they had. 11-year-olds had significantly higher attachment scores than 13-year-olds, who, in turn, had significantly higher scores than 15-year-olds.

According to Esposito, McCune, Griffin, and Maholmes (2011: p. 205-206), “major developmental changes in how children interact with pets are generally parallel to the developmental changes in interaction patterns that children have with familiar humans, including parents, siblings, and peers". Adolescence is a period of development when there are significant changes to the organization of the human attachment system, with rapid changes in friendships and attachment behaviors, as their focus of attention shifts. Research has often highlighted the distancing of adolescents from family and a new heightened focus on peers. However, a supportive family life is likely to become increasingly important as adolescents try to cultivate independence as well as socially acceptable/desirable identities among peers. Previous childhood identifications often need to be synthesized into a new configuration (Kroger, 2017). This often happens as a result of challenges or transitions in life, when there is recognition that a previous identity does not 'fit' a new social setting or developmental phase (Muldoon, 2005).

Set against this backdrop, whether pets feature less in children's broader attachment relationships as they move into adolescence is yet to be established. Entry into adolescence can be accompanied by increased conflict with parents (Branje, 2018; Marceau et al., 2015), so pets may provide a safe haven in the midst of anguish in other relationships. There are also likely to be qualitative changes in relationships with pets as children age, perhaps from active playmates to a non-judgmental source of support and comfort (Black, 2002; Muldoon et al., 2019). Van Houtte and Jarvis (1995) suggest that pets may even have their greatest impact on children's lives as they enter adolescence, as they found significant differences between those with and without pets in their feelings of autonomy, self-concept and self- 
esteem. Similarly, the 12-year-olds in Cassels et al.'s (2017) study reported more satisfaction and less conflict with their pets than with their siblings. Other studies have found therapeutic benefits of animals for vulnerable adolescent populations (e.g., Banman, 1995; Endenberg \& van Lith, 2011; Rew, 2000), suggesting that a relationship with, and attachment to, an animal is developmentally significant, at least in certain circumstances. Recent studies have also shown that the presence of dogs can benefit pre-adolescents in socially stressful situations (Kerns, Stuart-Parrigon, Coifman, van Dulmen, \& Koehn, 2017; Kertes, Liu, Hall, Hadad, Wynne, \& Bhatt, 2017).

Importantly, pets may still provide an important relationship even if adolescents begin to distance themselves from involvement with pets or self-present as disinterested. Charles and Davies (2008) highlight a cultural tendency among adults to deny that pet animals are significant in their lives, in case this is judged by others to be either childish or evidence that they are incapable of developing relationships with other human beings. Adolescents inevitably become increasingly aware of these cultural assumptions and prejudices (Levy, Ramirez, Rosenthal, \& Karafantis, 2013). It is also possible that pets are more associated with family life, and so feature more strongly in younger children's lives and narratives. We do not know, as yet, how changes in relationships experienced by the developing adolescent, and the extension of relationships/attachments beyond the family home, impacts on an existing child-pet bond. Nor do we know whether the stability of this relationship supports (or hinders) them in their navigation of relational changes. While there is growing evidence of the potential importance of adolescents' relationships with animals, the nature of emotional attachments to pets and how these might vary among different age groups, and between girls and boys, have received scant research attention.

\section{The influence of gender with respect to relationships with animals}


Some relationships are more important to girls than boys (Ma \& Huebner, 2008). In terms of the human attachment literature, girls are described as being more active in the pursuit of relatedness (Cross \& Madson, 1997); more strongly attached to parents, as well as more likely to draw support from other sources. Independence often characterises boys' behavior in relationships, and they often appear less attached to peers, as well as less satisfied with social life in school (Crosnoe \& Elder, 2004; Cross \& Madson, 1997). Accordingly, we may see these differences played out in the context of their relationships with pets. Girls may seek stronger emotional connections to their pets than boys. There is no consensus within existing research in relation to this suggestion. Some studies highlight the similarities between boys and girls in their overall attachment to a favourite pet (Westgarth et al., 2013) and in the separate behavioral, cognitive, and affective components of attachment (Melson, Peet, \& Sparks, 1991). Other studies have found that girls are more likely to desire and own pets, and express greater emotional connection to them (Paul \& Serpell, 1992; Ray, 1982; Rost \& Hartmann, 1994).

Findings that are suggestive of differences are consistent with the human attachment literature and more recent studies that find girls reporting stronger attachment to pets (MarsaSambola et al., 2016; Muldoon et al., 2019). While Melson (1990) considered animal care to be 'gender neutral', this finding has not been echoed in recent work by Muldoon et al. (2015) particularly, for example, with respect to cleaning out pets cages. Hawkins and Williams (2017) also found that girls scored significantly higher on caring behaviour, friendship behaviour, and compassion towards pets. Additionally, recent research has begun to highlight differences in the qualities of boys' and girls' relationships with pets. Cassels et al. (2017), for example, found that girls reported more disclosure and companionship with their pet, but also more conflict (quarrelling, getting upset with or mad at each other). 
Tipper (2011) argues that issues of gender and generation overlap in interactions with pets. Role models, distribution of activities and care-giving within the family (Muldoon et al., 2015), and wider societal portrayals of human relationships with animals, each potentially influence gendered roles. Children are likely, with age, to become increasingly susceptible to the effects of the social dimensions outlined above, as their experience and awareness of the implications of behaving certain ways grow ever more sophisticated. Increasing pressure to conform to adult gender stereotypes also typifies the move into early adolescence (Chawla, 1988; Muldoon, Williams, \& Lawrence, 2015; Tipper, 2011).

Observational studies of child-pet interactions have also revealed differences between girls and boys, but it is not always clear if other factors (social skills, or the context for interaction, for example) are more influential. Wedl and Kotrschal (2009) found that girls tended to engage more with rabbits that were introduced into the classroom, but pet owning and having siblings also had an effect on the frequency and duration of their interactions. In another study, while there was no difference in actual engagement, boys altered their behavior more in the presence of a dog. They were less likely to act aggressively and more attentive to the teacher (Kotrschal \& Ortbauer, 2003). So, while girls may show signs of stronger emotional attachment to pets overall, do they simply score higher on certain dimensions of the attachment relationship? According to Rost and Hartman (1994), the quality of emotional contact depends on whether the child is male or female, but also on pet type.

\section{Is pet type influential in determining the strength and nature of attachment?}

It is becoming clear within the HAI field that there is a need to look beyond pet attachment per se to examine the nature of the bond that develops with specific types of companion animal, as well as differential effects of perceived support from them (Stammbach \& Turner, 1999). In a previous paper using the same dataset (Muldoon et al., 
2019), dog owners were more strongly attached than those with other types of animal and there were significant differences between those who were strongly attached to their dogs in various measures of socio-emotional wellbeing. There were some positive associations for those with strong attachments to cats and small mammals but no obvious benefits of having a strong attachment to a fish/reptile/amphibian.

Muldoon et al. (2019) also examined individual components of the attachment measure, looking at differences according to pet type. Owners of dogs had the highest scores across all nine items. The most obvious areas of significant difference were in relation to spending time playing with them, believing their pet understands and comforts them, and feeling lonely without them. Dog owners were also significantly more likely than cat owners to consider their pet a friend. Nonetheless, adolescents' relationships with dogs may be qualitatively different to those of younger children, as the former tend to refer to dogs' ability to communicate, 'listen' and 'understand' them (Muldoon et al., 2016; Nevers et al., 1997), rather than them being good playmates. More recently, Hawkins and Williams (2017) found that only ownership of dogs and cats predicted attachment to pets.

\section{Understanding the qualities of child/adolescent attachments to pets}

This paper responds to Mueller's (2014a) claim that the developmental processes associated with HAI have not been adequately explored. In her initial analysis of the links between HAI and positive youth development, Mueller (2014b) argues that a nuanced understanding is required that moves beyond the dichotomization of interacting or not interacting with animals. Instead, there is a need to explore the qualities of those relationships and specific features of various animal experiences that may be associated with promoting positive development. Having already established with our sample that there are age differences in adolescents' attachment to pets (weaker attachment with increasing age), girls show higher levels of attachment, and dog owners report stronger attachment to their 
pet/s than owners of other types of companion animal, this paper endeavours to examine the nature of these differences in attachment in greater depth. We investigate whether there is any evidence suggesting differing developmental pathways of attachment for girls and boys during early to mid-adolescence with respect to the three most common pet types: dogs, cats and small mammals. Based on the literature and our prior work, we anticipated that:

(1) There might be interactions between age, sex, and the type of pet owned in early-mid adolescents' patterns of attachment.

(2) Early adolescents (pre-transition to secondary school at age 11 in Scotland) would view their relationship with their pet differently than older adolescents (i.e., the ratings given to different qualities of the relationship would vary between 11, 13 and 15 year olds).

(3) Girls would differ from boys in the specific qualities they attribute to their relationships with their pet/s (girls perhaps more likely to see their pets as a source of social and emotional support).

(4) Attachment to dogs may be more resistant to variation across age and sex than attachment to other pets, and characterised by greater emotional connection.

\section{Method}

\section{Sample}

The baseline sample, from which a smaller sub-sample was drawn for analysis, included all children/adolescents who responded to questions about pet ownership in the 2010 Scottish HBSC survey ( $\mathrm{n}=6,700$; age 11 [1021 boys, 1044 girls], age 13 [1060 boys, 1043 girls], age 15 [1209 boys, 1323 girls]). Children/adolescents who owned different types of pet animal (e.g., a cat and a dog) were eliminated from the analyses, as it was impossible to ascertain the animal type children were thinking about when they were answering the questions (they were asked to think about their relationship with their pet). Participants were grouped according to 
whether they had a dog/s, cat/s or small mammal/s. Table 1 details the distribution of pet ownership within the sample.

\section{Procedure}

The HBSC study is a large-scale international survey, collecting data every four years on 11, 13 and 15-year-olds' health and well-being, social environments and health behaviours (see http://www.hbsc.org). The surveys within each country are designed to be nationally representative using stratified random sampling, and are administered in schools by teachers, following precise instructions. On completion, pupils place their questionnaires in sealed envelopes to preserve anonymity. More detailed procedures are described in the HBSC National Report (Currie et al., 2011) and the International Protocol (Currie et al., 2010).

\section{Measures}

The 'Short Attachment to Pets Scale' (SAPS) (Muldoon \& Williams, 2009; MarsaSambola et al., 2016) was incorporated into the 2010 HBSC Scotland study to allow exploration of the nature and impact of pet attachment with a large sample. The SAPS was developed to capture succinctly the overall strength of children and adolescents' attachments to their pets within large scale surveys. In our case, the inclusion within HBSC permitted identification of any relationships with measures of socio-emotional wellbeing. This has been the focus of previous articles (Marsa-Sambola et al., 2016; 2017; Muldoon et al., 2019); the measure being used as a general approach to capturing a child/adolescent's attachment to a pet. In Marsa-Sambola et al.'s (2016) validation of the SAPS, Factor Analysis revealed a one-factor solution (explaining $67.78 \%$ of the variance). Cronbach's alpha for the scale was .89 , the item-total correlation ranged from .37 to .78 . The measure was developed in the process of undertaking focus groups with children that highlighted aspects of their relationships with favourite pets (Muldoon \& Williams, 2009). Items were further developed 
using existing US measures to match UK children's perspectives. This makes the case for detailing responses to each item of the SAPS.

The SAPS consists of nine items concerning children's/adolescents' attachment to pets: friendship/companionship (e.g., I consider my pet to be a friend); mutual understanding (e.g., I have sometimes talked to my pet and understood what it was trying to tell me), shared activities (e.g., I spend time every day playing with my pet), and emotional support that link to the concepts of a 'safe haven' or 'secure base' (e.g., My pet knows when I'm upset and tries to comfort me, I feel lonely without my pet). Two questions assessed their feelings about animals and pets generally. Participants were asked to respond on a 5-point Likert scale $(1=$ Strongly agree, $5=$ Strongly disagree $)$ and a mean score was calculated across the nine items. For treatment of missing scores on items see below.

\section{Analysis}

Univariate analysis of variance (ANOVA) using the General Linear Modelling procedure in SPSS was used to examine broad differences in the SAPS across age, sex, and pet type. We excluded 27 cases from the analysis of the SAPS as a whole because they had incomplete data on this scale (more than two questions had been missed out). If participants missed out only one or two of the nine questions, we retained their data, as there was no difference in the results when they were excluded. Next, multivariate ANOVA was used to examine the specific qualities of attachment that characterise early-to-mid adolescent boys' and girls' relationships with different types of pet. Partial eta squared is provided as a measure of effect size.

\section{Results}

\section{Differences in attachment overall (mean score on the SAPS)}

The ANOVA of the mean SAPS score revealed that boys and girls are similar in their age-related patterns of attachment; there were no interaction effects, but a gradual decrease in 
the strength of reported attachment with increased age $\left(F(2,2423)=110.37, p<.001, \eta p^{2}=\right.$ .08 , age $11 m=4.17$, s.d. $=.73$, age $13 m=3.87$, s.d. $=.76$, age $15 m=3.59$, s.d. $=.82$ ).

Girls' scores reveal stronger attachments to pets $(m=3.91$, s.d. $=.79$, compared with boys $m$ $=3.76$, s.d. $=.83)$. However, the difference between boys and girls $(F(1,2423)=39.42, p<$ $\left..001, \eta p^{2}=.02\right)$ is a small effect. Differences in attachment according to the type of pet were also confirmed $\left(F(2,2423)=47.45, p<.001, \eta p^{2}=.04\right)$. Dog owners show significantly stronger attachment to their pets $(m=3.94, s . d .=.78)$ than those with cats $(m=3.75, s . d .=$ $.84, p<.001, d=.23)$ or small mammals $(m=3.65, s . d .=.84, p<.001, d=.37)$.

Figure 1 shows that among dog owners, boys had significantly lower attachment scores than girls at all ages, but these effects were fairly small. Stronger effect sizes were found among cat owners, where boys had significantly lower attachment scores at age 15 years, and among owners of small mammals, where boys had significantly lower attachment scores at age 13 years.

\section{Examining differences in the qualities of the attachment relationship}

MANOVA using the nine individual items of the SAPS confirmed the main effect of age $\left(F(18,4622)=15.19, p<.001, \eta p^{2}=.06\right)$. Analysis of individual items revealed age differences across the board, significant at $p<.01$ or $p<.001$. As Figure 2 shows, small effect sizes were found in relation to understanding the pet, playing and talking, and medium effect sizes for loving pets, pet gives comfort or makes child happy, and feeling lonely. The largest effect size was found for the pet being a friend. With the exception of 'liking animals', differences were significant between all age groups.

Differences between girls and boys was also confirmed $(F(9,2310)=13.45, p<.001$, $\left.\eta p^{2}=.05\right)$. Analysis of individual items revealed significant differences at either $p<.005$ or $p<.001$, with the exception of the pet being a friend, where there was no significant difference between boys and girls. However, effect sizes were extremely low $(<.01)$ for 
most items. The exceptions, where small effect sizes were found, were in relation to girls being more likely to report loving pets, talking to them, and feeling lonely without them (see Figure 3).

Finally, the main effect of pet type was confirmed $\left(F(18,4622)=14.45, p<.001, \eta p^{2}\right.$ $=.05$ ), with analysis of individual items revealing differences between owners of different types of pet on all items of the SAPS, significant at $p<.01$ or $p<.001$. Adolescents with dogs scored higher on all of the relationship qualities, and those with cats scored higher than those with small mammals on two of the measures: the pet making them happy and comforting them. Inspection of eta squared values revealed small effect sizes for the majority of items, with slightly larger effects for playing with pet, pet being a friend and feeling lonely without them. However, a medium to large effect size was found for the pet giving comfort (see Figure 4).

\section{Discussion}

Main effects of age, sex, and pet type were found in attachment to pets, but no there were no interactions contrary to expectations (our first hypothesis). Accordingly, there is no evidence to suggest that there are different developmental pathways of attachment for boys and girls, although a longitudinal study would be necessary to ascertain with certitude. Our findings indicate that attachment to pets is stronger among younger adolescents, girls, and dog owners. However, the pattern of 15 -year-olds being less attached to their pets than 13 year-olds, and 13-year-olds being less attached than 11-year-olds, appears to be less pronounced where dogs are concerned, and less sex-dependent (see Figure 1). We discuss this later in relation to each of the main effects found. However, because age differences were the strongest, we discuss these first in relation to our hypotheses and theoretical implications. We then move on to discussing differences between girls and boys, and finally 
pet type. We end the Discussion with reflection on the limitations of the study and the practical implications of the findings.

\section{Age-related differences}

The second hypothesis that early-adolescents would view their relationship with their pet differently than older adolescents was confirmed. Although 11-year-olds scored higher than older adolescents on all relationship qualities (13-year-olds also scoring higher than 15year-olds), the most obvious differences were found in relation to loving pets, feeling that their pet made them happy, and comforted them, and feeling lonely. The largest effect size was found for the pet being a friend. This suggests a reliance on pets for comfort and happiness earlier in development with the lower scores among older adolescents perhaps reflecting a shift in focus towards peer acceptance and friendships rather than familial connections that tend to predominate earlier (Coleman, 2011; Esposito et al., 2011). Pets are viewed by younger children as part of the family so this developmental shift in human attachment (from family to peers) may also extend to relationships with pets (i.e., pets are likely to be more strongly associated with the family than the peer context).

Interestingly, attachment to dogs remains higher across all ages than attachment to cats or small mammals. This may be because relationships with dogs are easier to sustain when moving out of childhood. First, they can more easily move from the family to the peer group because dogs demand greater interaction within the home. Dog walking also necessitates being outside the home. This may lead to additional opportunities to interact with peers. Having a dog may also carry some prestige - it may not seem age-appropriate to enjoy playing with or cuddling other types of animal. Identity development, including social identity, is a core aspect of adolescence (Coleman, 2011; Kroger, 2017) and identification as a dog owner may become an important part of this. By contrast, pet care activities involving cats and small mammals are more focused within the home and family, and may confer fewer 
opportunities for peer group relationships, activities and social status/identity. Moreover, as a result of dogs' ability to relate to humans and the feeling of greater safety that they can bring to owners, they may act as an attachment figure (Carr \& Rockett, 2017) in a way that other animals simply cannot due to their cognitive and emotional abilities and behavioral repertoire.

\section{Differences between boys and girls}

Our third hypothesis, building on previous research, was that girls would differ from boys in terms of the qualities of their attachments to pets. This was confirmed with the exception of the pet being a friend. Pets are therefore clearly viewed as friends by both boys and girls, but the constituents of those friendships are different. This was one of the aspects of attachment that deteriorated most with age. Indeed, the differences between boys and girls were less statistically powerful overall than age-related or pet type differences.

Overall, while differences between girls and boys were small, the former scored higher on items relating to talking, receiving comfort, happiness and loneliness, aspects of attachment that might be interpreted as connected to emotional support. Cassels et al. (2017) similarly found girls reporting more intimate disclosure, companionship, and conflict with their pet than did boys. Such differences connect well with the psychological literature on gender differences in characteristics of peer relations and friendships in adolescence (Ma \& Huebner, 2008). Girls are more likely to draw on various sources of support and their friendships and social group ties focus more on emotional support and self-disclosure, whereas for adolescent males, friendships and peer groups are more bound by shared activities and interests (Rose \& Rudolph, 2006).

This may explain why the differences in the strength of boys' and girls' attachment to dogs are small overall, by contrast with other animals. Dogs may provide both the emotional support and comfort that girls seek out, and the active playmate and companion who can 
share activities with boys. The prestige aspect of having a dog, alluded to earlier, may also support boys' social identity development, particularly if the breed is one associated with masculinity, protection and status (Harding, 2014). There is evidence that dogs have a positive impact on social identity for men (Sanders, 1999); viewed as 'workout partners', and sometimes used as "props" in order to display masculinity (Kimmel \& Aronson, 2004). It is possible then that the attachments adolescents demonstrate with certain pets mirror the gendered nature of identity development and relationships with people, friendships especially.

\section{Pet type differences}

Our final hypothesis, that attachment to dogs may be more resistant to variation across age and sex than attachment to other pets, was confirmed in the sense that differences between male and female dog owners were very small at all ages, and attachment remains higher with dogs than other pets (Figure 1). By contrast, among cat owners, girls scored far higher than boys at age 15 years, and among small mammal owners at age 13 years. Daly and Morton (2003) also found no differences in the attachment of boys and girls to dogs, but large differences in attachment to cats. Accordingly, as we have just highlighted, relationships with dogs appear less susceptible to gendered influences and the effects of growing older. Identity and friendships are likely to be key factors here.

Having a dog is known to have a social facilitation effect among adults (McNicholas $\&$ Collis, 2000). However, heightened care behaviours are also needed for dogs (they require more attention, exercise and interaction) that may drive attachment relationships (Hawkins \& Williams, 2017). Modern human attachment theory focuses on parental attunement and synchronicity as essential for the formation of secure attachment among infants (Schore \& Schore, 2008). Dogs have co-evolved to interact with humans, altering their social behavior and reliance on certain senses, such that they are very responsive to human cues (Miklósi et 
al. 2005, Reid, 2009). Therefore, children may well form strong secure attachments to pet dogs in much the same way as siblings (Cassels et al., 2017). In the absence of secure attachments to parents, a pet dog may represent a significant other and a protective factor for children (Carr \& Rockett, 2017; Furnival, 2011).

Examining differences in the qualities of the relationships that adolescents have with their pets, we found that dog owners were more strongly attached than those with cats or small mammals across all items of the SAPS. Most of these were small effects, although slightly larger differences were found on the measures of playing together, the pet being a friend and feeling lonely without them (companionship/emotional support factors). Most striking though was the medium to large effect found for the pet giving them comfort. It is clear that dogs are important to both boys and girls, perhaps because they afford different forms of 'comfort'. For girls, they represent someone to share thoughts with (self-disclosure), for boys perhaps, someone to spend time with and share activities. It should be noted that cats were more likely to provide their owners with comfort and make them feel happy than those with small mammals.

\section{Limitations of the current study and implications}

There are several limitations of the study that need to be acknowledged and addressed in future research. The cross-sectional design permitted us to examine differences in attachment among different age groups of adolescents, but not developmental changes in the same individuals. Nevertheless, age differences are commonly used as a proxy for developmental changes when the age range is short and large cohort effects are not expected (Currie et al., 2012). A further limitation is that we have not captured the entire population of dog, cat and small mammal owners, as those with different types of pet had to be excluded to enable the examination of differences according to the type of pet in the household. The large sample size should not unduly bias the findings. The same argument could also be 
applied to sibling factors that were not investigated in the study that might affect the strength of attachment to pets. It is known that youngest or only children tend to have stronger attachment to their pets (Westgarth et al., 2013). We did not examine residential (urban/rural) or ethnicity factors that may be important. Nor did we examine socio-economic factors, although other studies using the SAPS have shown that this is not influential (Hawkins, Williams, \& Scottish SPCA, 2017).

In terms of the measure of attachment, the SAPS, while validated for use with children and adolescents (Muldoon \& Williams, 2009; Marsa-Sambola et al., 2016), and developed in the context of listening to children talking about their pets, at present the measure lacks convergent validity. This would have been achieved had we employed another measure of attachment, but this was not possible due to length limits imposed by the need to incorporate it into the already large and established HBSC survey (Currie \& AlemánDíaz, 2015; Currie, Watson, \& Rice, 2015). It is also possible that we have not captured all the different qualities of the attachment relationship. Indeed, given that girls are more likely to self-disclose, it poses the question of whether our measure adequately assesses boys' relationships. Personality differences may also play a role in the need for attachment to pets, as well as the social and emotional competences required to form attachments (Wedl \& Kotrschal, 2009). In relation to pets, human attunement to them requires an understanding of animal minds (sentience) and their pet's welfare needs, including knowledge of the natural behavior of the species (Hawkins, Williams, \& Scottish SPCA, 2016; Menor-Campos, Hawkins, \& Williams, 2018; Muldoon et al., 2016). Adolescents with a poor understanding of animal minds may be less likely to form attachments (especially secure attachments) to their pets.

The SAPS measure is unlikely to tap into 'insecure' or less adaptive forms of attachment. Insecure attachment to a pet, an over-reliance on pets for social and emotional 
support during adolescence, or avoidant patterns of attachment (where they do not seek emotional connection/support and may be unresponsive to the pet's needs), may interfere with aspects of human attachment development and peer relationships (see Mueller, 2014b). Alternatively, a strong relationship with a pet may act as an important resource for adolescents experiencing social and emotional difficulties or those with a history of family dysfunction and impaired attachment (Carr \& Rockett, 2017; Cassels et al., 2017). Exploring the quality of attachments in adolescents' relationships with pets and the 'nuances' as Mueller (2014b) describes, is an important avenue for future research. It also carries practical significance for those working with vulnerable children and adolescents.

Professionals might usefully assess the significance of pets in children's and adolescents' lives, and identify ways of managing loss or enabling continued contact, for example, in the case of children who need to move away from the family home. Pets within foster homes or residential settings may actually form part of the process of helping a child (a) gain a sense of belonging, and (b) develop a relationship with carers. They may act as a bridge to re-building children's trust in others (Carr \& Rockett, 2017; Furnival, 2011). Muldoon and Williams (2018) suggest that because pets provide children/adolescents with a rare opportunity to take on a caretaker role, when they are typically the recipients of care (Morrow, 2008), this may help develop a sense of autonomy, competence and confidence. Nonetheless, we also need to recognise that the most vulnerable children and adolescents may well have negative associations with respect to animals. They may have observed cruelty or been cruel to animals themselves through lack of knowledge or a way of dealing with emotional trauma. Alternatively, a beloved pet may no longer be with them through death or disappearance (getting lost).

To develop our understanding of the reasons behind the apparent diminishing of pet attachment, and establish whether or not relationships with pets actually remain important, 
future studies need to engage more closely with the views of children/adolescents and their families. In our previous paper (Muldoon et al., 2019), we argued that detailed qualitative studies of different family members' perceptions of children's/ adolescents' relationships (including the role each pet plays in their lives) would be extremely useful in helping to identify specific aspects of the relationship that contribute to specific aspects of wellbeing. A longitudinal dimension would also help to determine the significance of pets as children move through different phases of development.

In previous studies, we have demonstrated attachment links with child/adolescent mental health and wellbeing (Muldoon et al., 2019), as well as family communication (Marsa-Sambola et al., 2016). Accordingly, it is important to understand the interrelationships between the qualities of attachment to animals and other aspects of human social functioning; the relationship with the pet can perhaps be viewed as a barometer of an adolescent's social interactions with the wider world. There is mounting evidence of the positive effects of interactions with animals on anxiety and social cohesion (Kerns et al., 2017; Kertes et al., 2017; Kotrschal \& Ortbauer, 2003; McNicholas \& Collis, 2000), suggesting that animals might usefully be employed within schools, community and healthcare settings. Including animals in therapeutic settings is becoming increasingly popular, and some have been evaluated experimentally (e.g., Harris \& Williams, 2017). However, good quality evaluations are currently lacking (Stern \& Chur-Hansen, 2013).

\section{Conclusion}

This paper examines differences in the strength and quality of attachment to different pets reported in early to mid-adolescence, an area that has received little attention in HAI research. Our findings indicate that attachment to pets is stronger among younger adolescents, girls, and dog owners. There were no interactions between age, sex and pet type, so no evidence to suggest different developmental pathways for boys and girls. 
Substantial differences were found in relation to age and pet type, with younger adolescents relying more on pets for comfort, happiness and friendship. Relationships with dogs appear less susceptible to gendered influences and the effects of growing older, affording far greater comfort and friendship than relationships with cats and small mammals. Differences between girls and boys were small, but the former scored higher on items relating to emotional support (talking, loneliness, comfort). Given previous findings that link strong attachments to animals with positive physical and mental health outcomes (O'Haire, 2010), it is important that we understand the facilitative and protective functions of animals as we transition through different life stages. This area has been largely overlooked within developmental psychology. 


\section{References}

Amiot, C. E., \& Bastian, B. (2015). Toward a psychology of human-animal relations. Psychological Bulletin, 141(1), 6-47.

Banman, J. K. (1995). Animal-assisted therapy with adolescents in a psychiatric facility. Journal of Pastoral Care and Counselling, 49(3), 274-278.

Black, K. (2012). The relationship between companion animals and loneliness among rural adolescents. Journal of Pediatric Nursing, 27(2), 103-112.

Branje, S. (2018). Development of parent-adolescent relationships: Conflict interactions as a mechanism of change. Child Development Perspectives, 12(3), 171-176.

Bucci, S., Roberts, N. H., Danquah, A. N., \& Berry, K. (2015). Using attachment theory to inform the design and delivery of mental health services: A systematic review of the literature. Psychology and Psychotherapy: Theory, Research and Practice, 88(1), 1-20.

Carr, S., \& Rockett, B. (2017). Fostering secure attachment: experiences of animal companions in the foster home. Attachment \& Human Development, 19(3), 259-277.

Cassels, M. T., White, N., Gee, N., \& Hughes, C. (2017). One of the family? Measuring young adolescents' relationships with pets and siblings. Journal of Applied Developmental Psychology, 49, 12-20.

Cassidy, J., \& Shaver, P. R. (Eds.) (1999). Handbook of Attachment: Theory, Research and Clinical Applications. New York: The Guilford Press.

Cassidy, J., Jones, J. D., \& Shaver, P. R. (2013). Contributions of Attachment Theory and research: A framework for future research, translation, and policy. Development and Psychopathology: A Vision Realized, 25(4), 1415-1434.

Charles, N., \& Davies, C. A. (2008). My family and other animals: Pets as kin. Sociological Research Online, 13(5), 4. Available at http://www.socresonline.org.uk/13/5/4.html Chawla, L. (1988). Children's concern for the natural environment. Children's Environments 
Quarterly, 5(3): 13-20.

Chur-Hansen, A., McArthur, M., Winefield, H., Hanieh, E., \& Hazel, S. (2014). Animalassisted interventions in children's hospitals: A critical review of the literature. Anthrozoös: A multidisciplinary journal of the interactions of people and animals, 27(1), $5-18$.

Coleman, J. (2011). The Nature of Adolescence (4th Ed.) Hove, UK: Routledge.

Currie, C., \& Alemán-Díaz, A. Y. (2015). Building knowledge on adolescent health: reflections on the contribution of the Health Behaviour in School-aged Children (HBSC) study. European Journal of Public Health, 25(2), 4-6.

Currie, C., Griebler, R., Inchley, J., Theunissen, A., Molcho, M., Samdal, O., \& Dür, W. (Eds.) (2010). Health Behaviour in School-aged Children (HBSC) Study Protocol: Background, Methodology and Mandatory Items for the 2009/10 Survey. St Andrews, Child and Adolescent Health Research Unit, Vienna, Ludwig Boltzmann Institute of Health Promotion Research. Available from http://www.hbsc.org.

Currie, C., Levin, K. A., Kirby, J. L. M., Currie, D. B., van der Sluijs, W., \& Inchley, J. C. (2011). Health Behaviour in School-aged Children: World Health Organisation collaborative cross-national study (HBSC): findings from the 2010 HBSC survey in Scotland. HBSC Scotland National Report. Edinburgh, UK: Child and Adolescent Health Research Unit (CAHRU).

Currie, C., Watson, L., \& Rice, P. (2015). Adolescent health in the $21^{\text {st }}$ century. Journal of the Royal College of Physicians of Edinburgh, 45, 258-260.

Currie, C., Zanotti, C., Morgan, A., Currie, D., De Looze, M., Roberts, C., Samdal, O., Smith, O, R, F., \& Barnekow, V. (Eds.) (2012). Social determinants of health and wellbeing among young people. Health Behaviour in School-aged Children (HBSC) study: 
international report from the 2009/2010 survey. Copenhagen, WHO Regional Office for Europe, 2012 (Health Policy for Children and Adolescents, No. 6).

Daly, B., \& Morton, L. L. (2003). Children with pets do not show higher empathy: A challenge to current views. Anthrozoös: A multidisciplinary journal of the interactions of people and animals, 16, 298-314.

Endenberg, N., \& van Lith, H. A. (2011). The influence of animals on the development of children. The Veterinary Journal, 190(2), 208-214.

Esposito, L., McCune, S., Griffin, J. A., \& Maholmes, V. (2011). Directions in humananimal interaction research: Child development, health, and therapeutic interventions. Child Development Perspectives, 5(3), 205-211.

Furnival, J. (2011). Attachment-informed practice with looked after children and young people. The Institute for Research and Innovation in Social Services (Iriss). www.iriss.org.uk/resources/insights/attachment-informed-practice-looked-after-childrenyoung-people (Accessed 25/05/18).

Garrity, T. F., Stallones, L., Marx, M. B., \& Johnson, T. P. (1989). Pet ownership and attachment as supportive factors in the health of the elderly. Anthrozoös: A multidisciplinary journal of the interactions of people and animals, 3(1), 35-44.

Galvin, S. L., \& Herzog, H. A. (1998). Attitudes and dispositional optimism of animal rights demonstrators. Society \& Animals, 6(1), 1-11.

Harding, S. (2014). Unleashed: The phenomena of status dogs and weapon dogs. Bristol, UK: Policy Press.

Harris, A., \& Williams, J.M. (2017). The impact of a horse riding intervention on the social functioning of children with Autism Spectrum Disorder. International Journal of Environmental Research and Public Health, 14(7), 776. 
Havener, L., Gentes, L., Thaler, B., Megel, M., Baun, M., Driscoll, F., Beiraghi, S., \& Agrawalet, N. (2001). The effects of a companion animal on distress in children undergoing dental procedures. Issues in Comprehensive Pediatric Nursing, 24(2), 137 152.

Hawkins, R. D., \& Williams, J. M. (2017). Childhood attachment to pets: Associations between pet attachment, attitudes to animals, compassion, and humane behaviour. International Journal of Environmental Research and Public Health, 14(5), 490.

Hawkins, R. D., Williams, J. M., \& the Scottish SPCA (2017). Assessing effectiveness of a nonhuman animal welfare education program for primary school children. Journal of Applied Animal Welfare Science, 20(3), 240-256.

Herzog, H. A. (2007). Gender differences in human-animal interactions: A review. Anthrozoös: A multidisciplinary journal of the interactions of people and animals, 20(1), $7-21$.

Herzog, H. A., Betchart, N. S., \& Pittman, R. B. (1991). Gender, sex role orientation, and attitudes toward animals. Anthrozoös: A multidisciplinary journal of the interactions of people and animals, 4(3), 184-191.

Jalongo, M. R. (2015). An attachment perspective on the child-dog bond: interdisciplinary and international research findings. Early Childhood Education Journal, 43(5), 395-405.

Kerns, K. A., Parrigon, K. S., Coifman, K. G., van Dulmen, M. H. M., \& Koehn, A. J. (2018). Pet dogs: Does their presence influence preadolescents' emotional responses to a social stressor? Social Development, 27, 34-44.

Kertes, D. A., Liu, J., Hall, N. J., Hadad, N. A., Wynne, C. D. L., \& Bhatt, S. (2017). Effect of pet dogs on children's perceived stress and cortisol stress response. Social Development, $26(2), 382-401$. 
Kimmel, M., \& Aronson, A. (Eds.) (2004). Men and Masculinities: A Social, Historical and Cultural Encyclopedia. Volume I: A-J. Santa Barbara, California: ABC-CLIO Inc.

Kotrschal, K., \& Ortbauer, B. (2003). Behavioral effects of the presence of a dog in a classroom. Anthrozoös: A multidisciplinary journal of the interactions of people and animals, 16(2), 147-159.

Kroger, J. (2017). Identity development in adolescence and adulthood. Oxford Research Encyclopedia of Psychology. Oxford University Press.

DOI:10.1093/acrefore/9780190236557.013.54.

Kurdek, L.A. (2009). Pet dogs as attachment figures for adult owners. Journal of Family Psychology, 23(4), 439-446.

Levy, S. R., Ramirez, L., Rosenthal, L., \& Karafantis, D. M. (2013). The study of lay theories: A piece of the puzzle for understanding prejudice. In M. R. Banaji, \& S. A. Gelman (Eds.), Navigating the Social World: What Infants, Children and Other Species can Teach Us (pp. 318-322). New York: Oxford University Press.

Limer, J., \& Lundahl, B. (2007). Animal-Assisted Therapy: A Meta-Analysis. Anthrozoös: A multidisciplinary journal of the interactions of people and animals, 20(3), 225-238.

Ma, C. Q., \& Huebner, E. S. (2008). Attachment relationships and adolescents' life satisfaction: Some relationships matter more to girls than boys. Psychology in the Schools, 45(2), 177-190.

Marceau, K., Zahn-Waxler, C., Shirtcliff, E., Schreiber, J., Hastings, P., \& Klimes-Dougan, B. (2015). Adolescents', mothers', and fathers' gendered coping strategies during conflict: Youth and parent influences on conflict resolution and psychopathology. Development and Psychopathology, 27(4pt1), 1025-1044.

Marsa-Sambola, F., Williams, J., Muldoon, J., Lawrence, A., Connor, M., \& Currie, C. (2017). Quality of life and adolescents' communication with their significant others 
(mother, father, and best friend): The mediating effect of attachment to pets. Attachment \& Human Development, 19(3), 278-297.

Marsa-Sambola, F., Muldoon, J., Williams, J., Lawrence, A., Connor, M., \& Currie, C. (2016). The Short Attachment to Pets Scale (SAPS) for children and young people: development, psychometric qualities and demographic and health associations. Child Indicators Research, 9(1), 111-131.

Mathers, M., Canterford, L., Olds, T., Waters, E., \& Wake, M. (2010). Pet ownership and adolescent health: Cross-sectional population study. Journal of Paediatrics and Child Health, 46, 729-735.

Mathews, S., \& Herzog, H. A. (1997). Personality and attitudes toward the treatment of animals. Society \& Animals, 5(2), 169-175.

McNicholas, J., \& Collis, G. M. (2000). Dogs as catalysts for social interactions: robustness of the effect. British Journal of Psychology, 91(1), 61-70.

McNicholas, J., \& Collis, G. M. (2001). Children's representations of pets in their social networks. Child Care, Health and Development, 27(3), 279-294.

Meehan, M., Massavelli, B., \& Pachana, N. (2017). Using Attachment Theory and Social Support Theory to examine and measure pets as sources of social support and attachment figures. Anthrozoös: A multidisciplinary journal of the interactions of people and animals, $30(2), 273-289$.

Melson, G. F. (1990). Studying children's attachment to their pets: A conceptual and methodological review. Anthrozoös: A multidisciplinary journal of the interactions of people and animals, 4(2), 91-99.

Melson, G. F., Peet, S., \& Sparks, C. (1991). Children's attachment to their pets: Links to socio-emotional development. Children's Environments Quarterly, 8(2), 55-65. 
Menor-Campos, D. J., Hawkins, R. D., \& Williams, J. M. (2018). Belief in animal mind among spanish primary school children. Anthrozoös: A multidisciplinary journal of the interactions of people and animals, 31(5), 599-614.

Miklósi, A., Pongrácz, P., Lakatos, G. Topál, J., \& Csányi, V. 2005. A comparative study of the use of visual communicative signals in interactions between dogs (Canis familiaris) and humans and cats (Felis catus) and humans. Journal of Comparative Psychology, 119, 179-186.

Morrow, V. (1998). My animals and other family: Children's perspectives on their relationships with companion animals. Anthrozoös: A multidisciplinary journal of the interactions of people and animals, 11(4), 218-226.

Morrow, V. (2008). Responsible children and children's responsibilities? Sibling caretaking and babysitting by school-age children. In J. Bridgeman, H. Keating \& C. Lind (Eds.). Responsibility, Law and the Family (pp. 105-124). Aldershot: Ashgate.

Mueller, M. K. (2014a). Human-Animal Interaction as a context for Positive Youth Development: A Relational Developmental Systems Approach to constructing humananimal interaction theory and research. Human Development, 57, 5-25.

Mueller, M. K. (2014b). Is Human-Animal Interaction (HAI) linked to Positive Youth Development? Initial answers. Applied Developmental Science, 18(1), 5-16.

Muldoon, J. C. (2005). The Significance of Teachers and Relational Change During Children's Psychological Transition to Secondary School. Lancaster University. Unpublished $\mathrm{PhD}$ thesis.

Muldoon, J. C., \& Williams, J. M. (2018). Children's emotional attachment to pets: the implications for vulnerable children. Caar Research Briefing 2, April 2018. University of Edinburgh. 
Muldoon, J. C., \& Williams, J. M. (2009). Developing questions for the HBSC study: Findings from the Defra funded project 'Promoting a Duty of Care towards animals among young people'. Edinburgh, UK: Child and Adolescent Health Research Unit (CAHRU).

Muldoon, J. C., Williams, J. M., Lawrence, A., \& Currie, C. (2019). The nature and psychological impact of child and adolescent attachment to dogs in comparison with other types of pet. Society \& Animals.

Muldoon, J. C., Williams, J. M., \& Lawrence, A. (2015). 'Mum cleaned it and I just played with it': Children's perceptions of their roles and responsibilities in the care of family pets. Childhood, 22(2), 201-216.

Muldoon, J. C., Williams, J. M., \& Lawrence, A. (2016). Exploring children's perspectives on the welfare needs of pet animals. Anthrozoös: A multidisciplinary journal of the interactions of people and animals, 29(3), 357-375.

Myers, O. E. Jr., \& Saunders, C. D. (2002). Animals as links toward developing caring relationships with the natural world. In P. H. Kahn Jr \& S. R. Kellert (Eds.) Children and Nature: Psychological, Sociocultural and Evolutionary Investigations (pp. 153-178). Cambridge, MA: MIT Press.

Nevers, P., Gebhard, U., \& Billmann-Mahecha, E. (1997). Patterns of reasoning exhibited by children and adolescents in response to moral dilemmas involving plants, animals and ecosystems. Journal of Moral Education, 26(2), 169-186.

O'Haire, M. (2010). Companion animals and human health: Benefits, challenges, and the road ahead. Journal of Veterinary Behavior: Clinical Applications and Research, 5(5), 226-234. 
Payne, E., Bennett, P. C., \& McGreevy, P. D. (2015). Current perspectives on attachment and bonding in the dog-human dyad. Psychology Research and Behavior Management, 8, 71 79.

Paul, E. S., \& Serpell, J. (1992). Why children keep pets: The influence of child and family characteristics. Anthrozoös: A multidisciplinary journal of the interactions of people and animals, 5(4), 231-244.

Plous, S. (1991). An attitude survey of animal rights activists. Psychological Science, 2(3), 194-196.

Prato-Previde, E., Fallani, G., \& Valsecchi, P. (2006). Gender differences in owners interacting with pet dogs: An observational study. Ethology, 112(1), 64-73.

Ray, J. J. (1982). Love of animals and love of people. The Journal of Social Psychology, 116(2), 299-300.

Reid, P. J. (2009). Adapting to the human world: Dogs' responsiveness to our social cues. Behavioural Processes, 80(3), 325-333.

Rew, L. (2000). Friends and pets as companions: Strategies for coping with loneliness among homeless youth. Journal of Child and Adolescent Psychiatric Nursing, 13(3), 125-132.

Rockett, B., \& Carr, S. (2014). Animals and Attachment Theory. Society \& Animals, 22(4), $415-433$.

Rose, A. J., \& Rudolph, K. D. (2006). A review of sex differences in peer relationship processes: Potential trade-offs for the emotional and behavioral development of girls and boys. Psychological Bulletin, 132(1), 98-131.

Rost, D. H., \& Hartman, A. (1994). Children and their pets. Anthrozoös: A multidisciplinary journal of the interactions of people and animals, 7(4), 242-254.

Sanders, C. R. (1999). Understanding Dogs: Living and Working with Canine Companions. Philadelphia: Temple University Press. 
Schore, J. R., \& Schore, A. N. (2008). Modern Attachment Theory: The central role of affect regulation in development and treatment. Clinical Social Work Journal, 36(1), 9-20.

Stammbach, K.B., \& Turner, D.C. (1999). Understanding the human-cat relationship: Human social support or attachment. Anthrozoös: A multidisciplinary journal of the interactions of people and animals, 12(3), 162-168.

Stern, C., \& Chur-Hansen, A. (2013). Methodological considerations in designing and evaluating Animal-Assisted Interventions. Animals, 3(1), 127-141.

Tipper, B. (2011). 'A dog who I know quite well’: Everyday relationships between children and animals. Children's Geographies, 9(2), 145-165.

Van Houtte, B. A., \& Jarvis, P. A. (1995). The role of pets in preadolescent psychosocial development. Journal of Applied Developmental Psychology, 16(3), 463-479.

Wedl, M., \& Kotrschal, K. (2009). Social and individual components of animal contact in preschool children. Anthrozoös: A multidisciplinary journal of the interactions of people and animals, 22(4), 383-396.

Westgarth, C., Boddy, L. M., Stratton, G., German, A. J., Gaskell, R. M., Coyne, K. P., Bundred, P., McCune, S., \& Dawson, S. (2013). Pet ownership, dog types and attachment to pets in 9-10 year old children in Liverpool, UK. BMC Veterinary Research, 9, 102. 


\section{Tables}

Table 1

Pet ownership in the sample

\begin{tabular}{|c|c|c|c|c|c|c|c|c|c|}
\hline \multirow[t]{2}{*}{ Owners of: } & \multirow[t]{2}{*}{ Sex } & \multicolumn{2}{|c|}{ 11-year-olds } & \multicolumn{2}{|c|}{ 13-year-olds } & \multicolumn{2}{|c|}{ 15-year-olds } & \multicolumn{2}{|c|}{ Total } \\
\hline & & $\mathrm{N}$ & $\%$ & $\mathrm{~N}$ & $\%$ & $\mathrm{~N}$ & $\%$ & $\mathrm{~N}$ & $\%$ \\
\hline \multirow[t]{3}{*}{$\operatorname{Dog} / \mathrm{s}$} & Boys & 196 & 27.8 & 230 & 29.8 & 293 & 29.5 & 719 & 29.1 \\
\hline & Girls & 178 & 25.2 & 198 & 25.6 & 329 & 33.1 & 705 & 28.5 \\
\hline & Total & 374 & 53.0 & 428 & 55.4 & 622 & 62.6 & 1424 & 57.6 \\
\hline \multirow[t]{3}{*}{$\mathrm{Cat} / \mathrm{s}$} & Boys & 93 & 13.2 & 92 & 11.9 & 122 & 12.3 & 307 & 12.4 \\
\hline & Girls & 92 & 13.0 & 123 & 15.9 & 146 & 14.7 & 361 & 14.6 \\
\hline & Total & 185 & 26.2 & 215 & 27.8 & 268 & 27.0 & 668 & 27.0 \\
\hline \multirow[t]{3}{*}{ Small mammal/s } & Boys & 58 & 8.2 & 66 & 8.5 & 42 & 4.2 & 166 & 6.7 \\
\hline & Girls & 88 & 12.5 & 64 & 8.3 & 62 & 6.2 & 214 & 8.7 \\
\hline & Total & 146 & 20.7 & 130 & 16.8 & 104 & 10.5 & 380 & 15.4 \\
\hline \multirow[t]{3}{*}{ Overall sample } & Boys & 347 & 49.2 & 388 & 50.2 & 457 & 46.0 & 1192 & 48.2 \\
\hline & Girls & 358 & 50.8 & 385 & 49.8 & 537 & 54.0 & 1280 & 51.8 \\
\hline & Total & 705 & 100.0 & 773 & 100.0 & 994 & 100.0 & 2472 & 100.0 \\
\hline
\end{tabular}




\section{Figure captions}

Figure 1: Differences in boys' and girls' attachment to pets at age 11, 13 and 15 years old Figure 2: Age differences in qualities of attachment (boys and girls, and all pet types) Figure 3: Differences between girls' and boys' in qualities of attachment to pets (all age groups and pet types)

Figure 4: Pet type differences in qualities of attachment (boys and girls, and all age groups) 


\section{Figures}

Figure 1

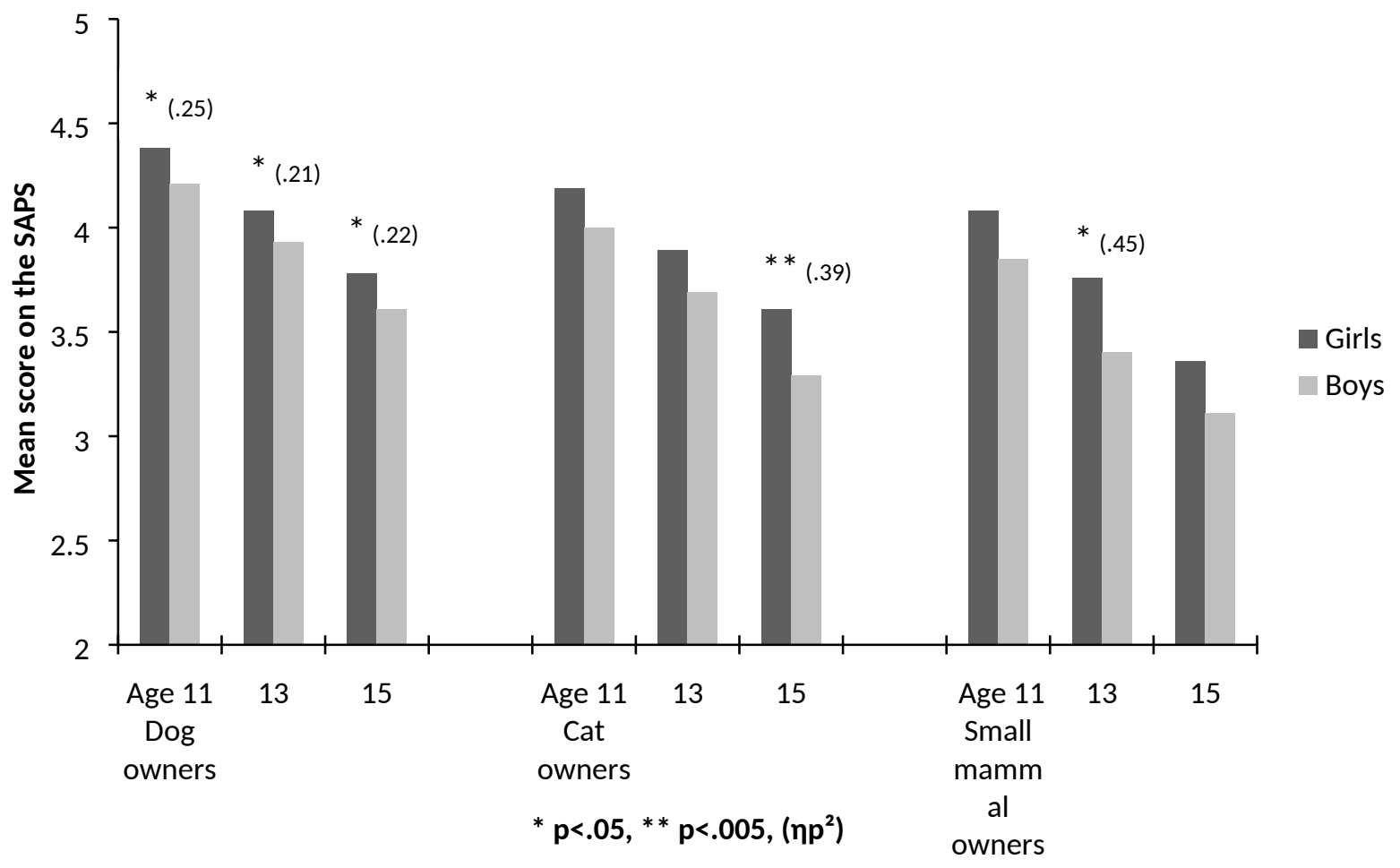


Figure 2

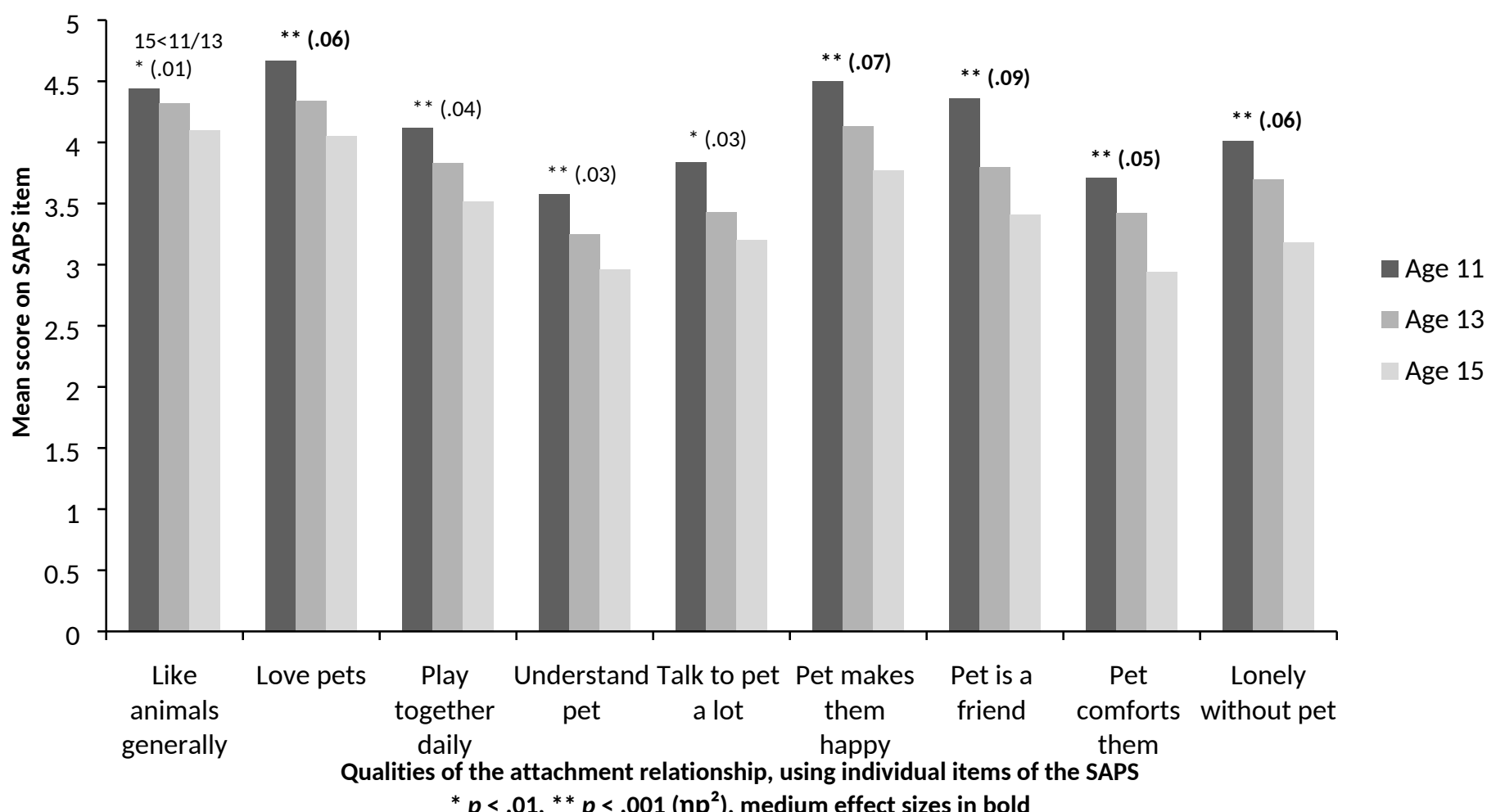


Figure 3

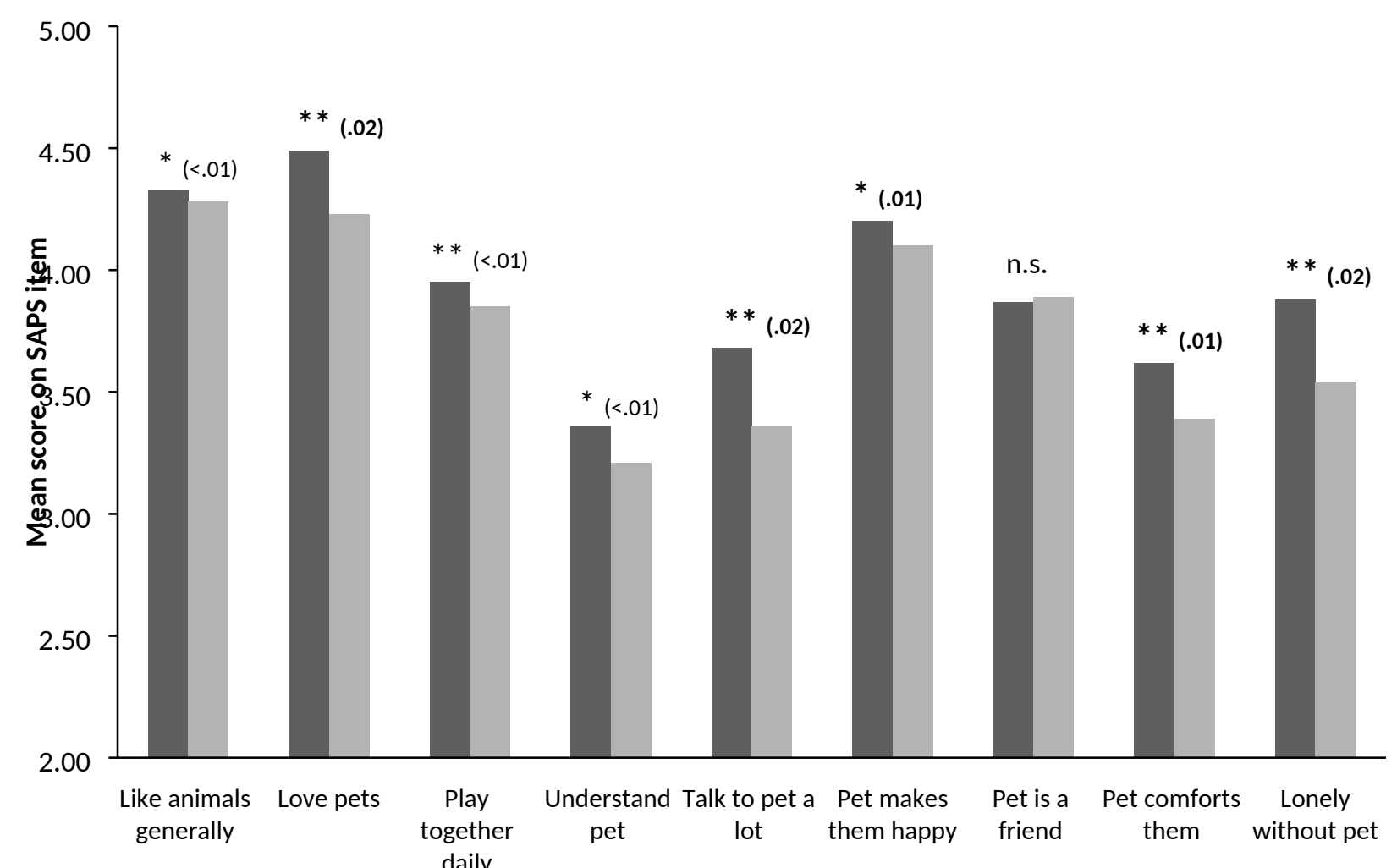

Girls

Boys

Qualities of the attachment relationship, using individual items of the SAPS

${ }^{*} p<.005,{ }^{* *} p<.001,\left(\eta p^{2}\right)$, small effects in bold 
Figure 4

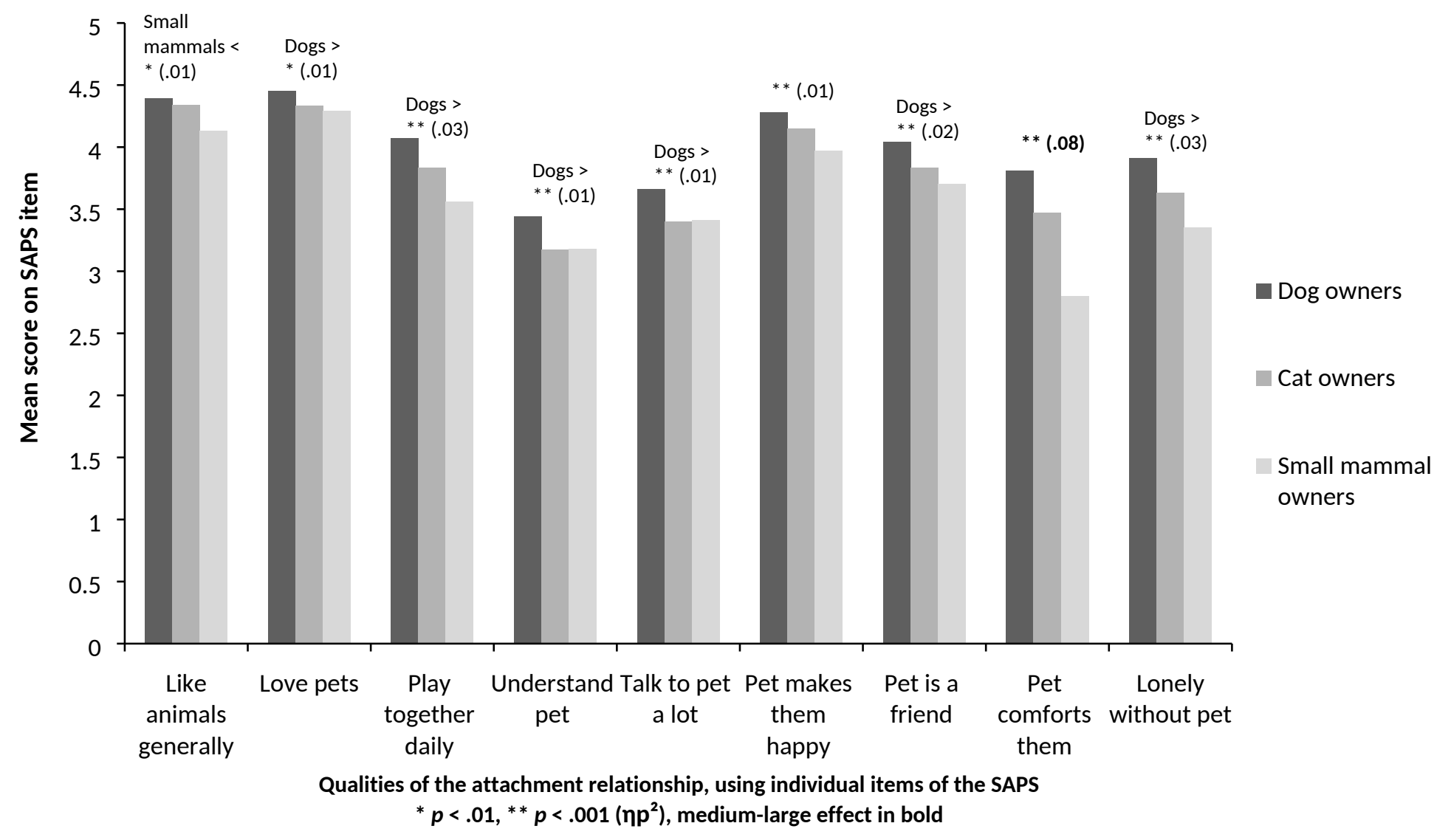




\section{Author Note}

Dr Janine C Muldoon (corresponding author), Clinical and Health Psychology, School of Health in Social Science, University of Edinburgh, Doorway 6, Medical Quad, Teviot Place, Edinburgh, UK, EH8 9AG. janine.muldoon@ed.ac.uk Tel: +44 (0)1383 861280

Professor Joanne M Williams, Clinical and Health Psychology, School of Health in Social Science, University of Edinburgh, Doorway 6, Medical Quad, Teviot Place, Edinburgh, UK, EH89AG. jo.williams@ed.ac.uk Tel: +44(0)1316509962

Professor Candace Currie, Child and Adolescent Health Research Unit (CAHRU), School of Medicine, Medical \& Biological Sciences, North Haugh, St Andrews, Fife, UK, KY16 9TF. cec53@st-andrews.ac.uk Tel: +44(0)1334 461741

\section{Funding}

This work was supported by the Department for Environment, Food and Rural Affairs [grant numbers AW1404 and AW1407].

\section{Acknowledgments}

We would like to thank the children and schools for participating in the research presented in this paper. We also acknowledge the national HBSC team in Scotland. 